\title{
Outlines of an Oil Spill Response Plan (OSRP) for Crude Oil Pipelines
}

\author{
Huseyin Murat Cekirge \\ Department of Mechanical Engineering, Prince Mohammad Bin Fahd University, Al Khobar, KSA \\ Email address: \\ hmcekirge@usa.net \\ To cite this article: \\ Huseyin Murat Cekirge. Outlines of an Oil Spill Response Plan (OSRP) for Crude Oil Pipelines. International Journal of Environmental \\ Monitoring and Analysis. Vol. 3, No. 3, 2015, pp. 191-197. doi: 10.11648/j.ijema.20150303.21
}

\begin{abstract}
The paper is presenting outlines of an Oil Spill Response Plan (OSRP) for a crude oil pipeline with onshore and offshore facilities. The methodology of preparing an OSRP plan is introduced in detail; however a case or numerical example is not presented. The methodology is not aimed at a specific crude oil pipeline, and the directions in the paper can be applied any pipeline. A structured tool for designing OSRP is introduced in detail.
\end{abstract}

Keywords: Oil Spill Response Plan, Safety of Oil Pipelines, Planning of Oil Pipelines, OSRP, Outlines of OSRP, Containments Sites

\section{Introduction}

This Oil Spill Response Plan (OSRP) provides guidance and methods to respond to oil spills generated from activities associated with the pipeline and marine terminal. It is valid for spills that may occur during the commissioning, operation and de-commissioning.

The pipeline and all the related onshore and offshore installations topographical, geological and meteorological conditions of the surrounding must be well defined to design an OSRP properly. The determination of response needs is based on risk assessments carried out for the pipeline, marine terminal and shipping lane. These analyses determined the probability of oil spillage, the distribution and spread of various spill sizes, and the potential impact to sensitive environments and wildlife. The risk assessment of the installation is identified potential spill volume loss by pipeline kilometer. Combined with the analysis of potential spill movement and the environmental sensitivity of potentially exposed areas, the optimum type and location of emergency response resources was determined.

A spill or a threat from a fault in the operation of the pipeline, marine terminal, and related facilities is controlled by procedures established by the OSRP. These procedures are for;

- minimizing movement of oil spills,

- minimizing environmental impact,

- maximizing effectiveness of response and equipment,
- protecting the environment,

- preventing spills from oil tanks and pipeline,

- preventing spills vessel operation and vessel accidents.

The accidents of outside area are responsibility of the pipeline operator. Oil spill response plans can be executed by the Incident Management System (IMS) for emergency response. The OSRP is the guidance in the initial and ongoing response to a release of oil spills. The plan is a dynamics document can be always be updated according to the events around the installation area, including Tier 2 and Tier 3 oil spills. The OSRP cannot be full proof response tool, in the case of outstanding cases, historical experiences and common sense, [1-16].

\section{Notifications and Reporting}

All spills must be reported to the pipeline owner and management. The call-outs may be extended base on the spill volume and further government agencies. These number must be in an appropriate data base and reachable by the Incident Commander, who is the leader of the event, for $7 / 24$ basis. The Incident Commander (IC) can contact all the concerned parties.

The components of Notifications and Reporting are:

- Internal Notification and Call-Out Procedure,

- Switchboard Operator,

- IMT Call-Out,

- Response Contractor Call-Out,

- Notification of Authorities, 
- Notifying Adjacent Industry,

- Notification for Trans-Boundary Spills,

- Call-Out Guidelines,

- Discovery,

- Incident Confirmation,

- Determining Scale of Response.

\section{Safety Considerations}

Spills are hazardous to spill responders, employees and the general public. A safe response is minimization of these hazards. The following information is necessary to assess conditions and hazards for the Incident's Site Safety Plan. The issues are:

Fire and Explosion Hazard

Shared Right of Way (ROW) and Power Transmission Lines

Risk Assessment

\subsection{Safety Overview}

Specific health and safety issues related to spill cleanup include the following:

Inhalation,

Effects of Contact with Oil,

Heat Exhaustion,

Cold Weather Conditions,

Working on Water,

Working in Fast Flowing Streams,

Working in Excavations,

Initial Safety Assessment,

On-site Safety Characterization,

Safe Approach Guidelines,

Off-Site Safety Characterization,

Safety Briefings and Announcements,

Public Information and Safety Alerts,

\subsection{Safety Issues}

Work Site Setup:

The oil spill response site must be set up international standarts. These are:

Hot Zone: The contaminated area where all the work carried out,

Warm Zone: The cross area.

Cold Zone: The clean supporting operations are carried out.

Decontamination (DECON):

The Decontamination is important for clean-up procedures, and these are;

Personnel Decontamination,

Equipment Decontamination.

Demobilization:

Demobilization is the process of cleaning and releasing equipment and resources that are not needed.

Security:

The pipeline management has developed a Security Plan for dealing with the operations along the pipeline system.
The safety plan must be ready for whole installations; it must consist of the following issues:

Hazards, Area Affected, Weather Conditions, Environmental, Archeological Areas, Additional Information, Site Access, Hazard Evaluation, Chemical Hazardous Substances, Material Safety Data Sheets (MSDS), Additional Hazards, Personal Protective Equipment (PPE), Decontamination, Communications, Personnel Identification, First Aid, Emergency Eye Wash Station, Potable water, Toilet Facilities, Air Monitoring, Additional Health and Hygiene Sampling, Emergency Procedures, Injury/Illness in the Area, Medevac Response, Personal Protective Equipment Failure, Other Equipment Failure.

\section{Spill Response Organization}

\subsection{Connection with IMS (Incident Management System)}

The Incident Management System (IMS) of the pipeline management is based on the Incident Command System (ICS) for handling the crisis situations. The Site Response Team (SRT) will manage Tier 1 spills, for Tier 2 and Tier 3 oil spills, the IMT will be activated, if necessary with external resources.

\subsection{Site Response Team (SRT)}

The SRT is made from the pipeline personnel and maybe trained contractors. The containment sites are also member of SRT. These personnel are:

On-Scene Manager (OSC),

Safety Manager,

Staging Area Manager,

Operations Personnel,

Planning Personnel,

Environmental Unit,

Logistics Personnel,

Security Personnel,

Waste Management,

Containment Site Manager(s).

\subsection{The Pipeline Owner IMT (Incident Management Team)}

A detailed description of the pipeline owner IMT is:

Incident Commander (IC),

On-Scene Commander (OSC),

Site Safety Officer,

Operations Section Chief,

Equipment Control Branch Director (Repair Supervisor),

Waste Management Unit Leader,

Wildlife Care Unit Leader,

Site Manager - Containment Sites,

Planning Section Chief,

Environmental Unit Leader,

Logistics Section Chief,

Security Unit Leader,

Documentation Unit Leader,

Finance /Administration Section Chief.

\subsection{Example Site Safety Plan}




\section{Logistics and Communications}

\subsection{Logistics}

Oil spills may happen in remote areas and logistic section is most important part the IMS, that is the part of Incident Action Plan. It is the liaison between Transport Centers, Command Posts and staging areas. Transport of general equipment, food, personal protective equipment, cold weather clothing, sanitation, security, medical help, waste, fuel during day and night time, and in all weather conditions is the main issue of the logistics.

\subsection{Communications}

The communication system contains in mobile telephones, satellite phones and VHF Radios. It should be noted that an emergency communication networks is necessary to handle crisis situations. The communication is in the control of the Incident Commander and the Communications Unit Leader of Logistics Section.

Crisis emergency Communications Network:

- Command Center Communications Room,

- Paging Equipment,

- Mobile Telephones,

- Press Room with Communication Equipment,

- Media/Public Affairs Support with Communication Equipment.

Total Crisis Communications:

- Terrestrial Telephones,

- GSM System,

- Communication providers,

- VHF Radios,

- Satellite Phone,

- Aircraft (ground to air) through VHF radios.

\section{Spill Assessment and Tracking}

A forecasting and trajectory model is necessary to follow and monitor the oil on land and sea. This program may help to resolve legal claims aftermath of the oil spill. Monitoring oil spills is;

- Spill Size Determination,

- Spill Movements,

- Spill tracking that help Incident Command. Shoreline Cleanup Assessment Teams (SCAT),

- Environmental Monitoring.

Oil spill can be initiated from oil tanks, terminal, open water, vessels, pipeline and land. OSRP must consist of detailed information for each case, [17-21]. Based on the size and location of the whole installation, equipment depots should be established; even considering air transport for equipment. The locations must be chosen for the most efficient response to onshore and offshore oil spills.

\subsection{Spills on Land}

On land oil spills start from pipelines and flow low spots by gravity and topographic contours and end up river beds, catchment areas. At the each kilometer point, an oil spill may start and reach a river bed, which is called "containment site". It is mostly required two containment site for every Kilometer Point, KP. The cleaning operations can performed at these containment sites, Figure 1, 2, 3 and 4.

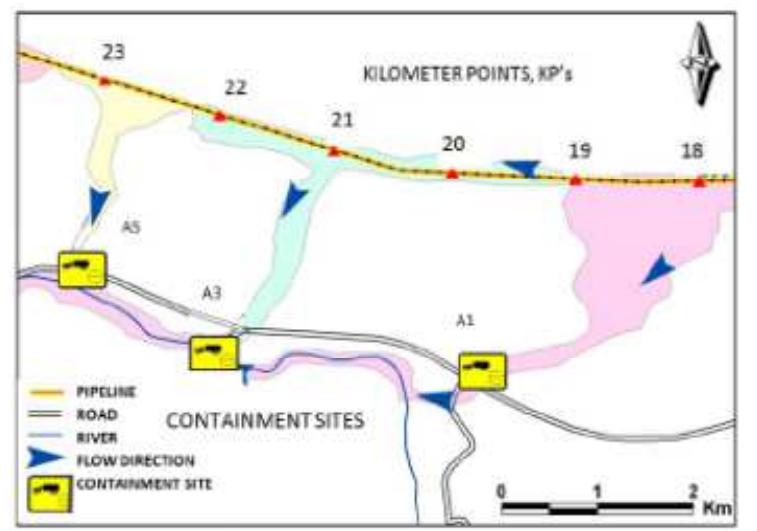

Figure 1. Down slope potential oil spill flow analysis (Catchment Area), related containment sites and pipeline KP (Kilometer Point), [22].

Each containment site must analyzed, the following information must be recorded pictures, maps and sketches:

- Description of the Site and directions,

- General Cleanup Options / Equipment,

- Environmental Sensitivity - Pipeline Corridor,

- Pipeline Crossing Information,

- Down Stream Environments.

The spills must be caught and cleaned from the equipment coming from equipment depots which are established best reachable location for containment sites, even considering Tier 1, Tier 2, and Tier 3.

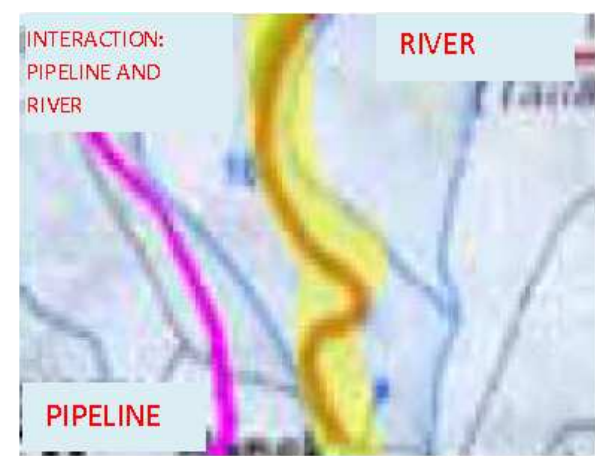

Figure 2. Map of pipeline, [22].

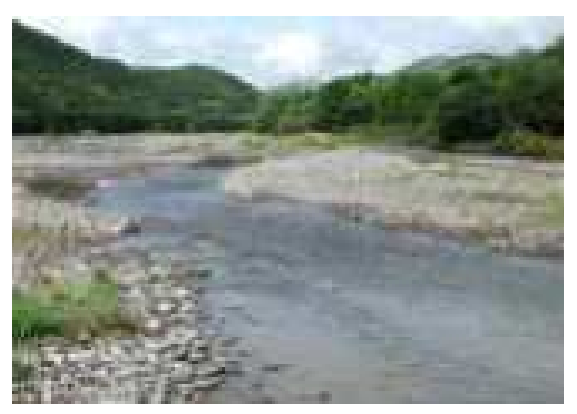

Figure 3. View of the containment site, [22]. 


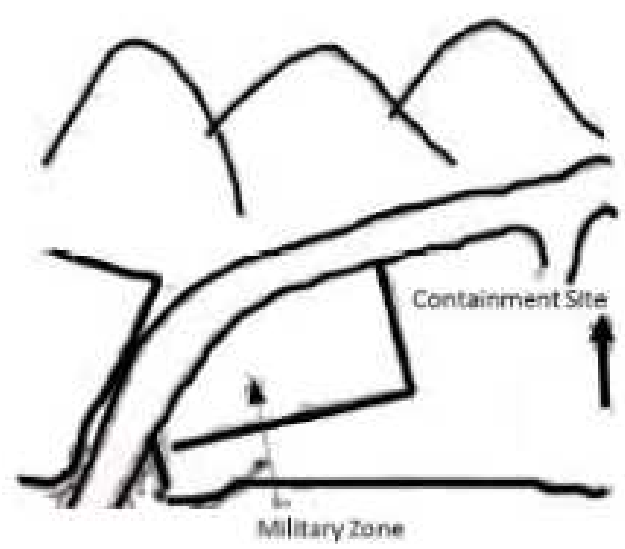

Figure 4. Sketch of the containment site, [22].

\subsection{Spills on Water}

Oil spills on water must be tracked on water by computer models or at least by using vector addition techniques. The oil spill can be caught in shoreline containment sites, Figures $5,6,7$, and 8. For cleaning purposes these containment sites should analyzed and loaded a data base. The necessary information is:

- Offshore Description of the site and directions,

- General Cleanup Options / Equipment,

- Response Actions,

- Coastal Sensitivity Maps.

The monitoring is to identify changes on the containment sites and the information must be always updated. This data will help clean up and mitigation operations.

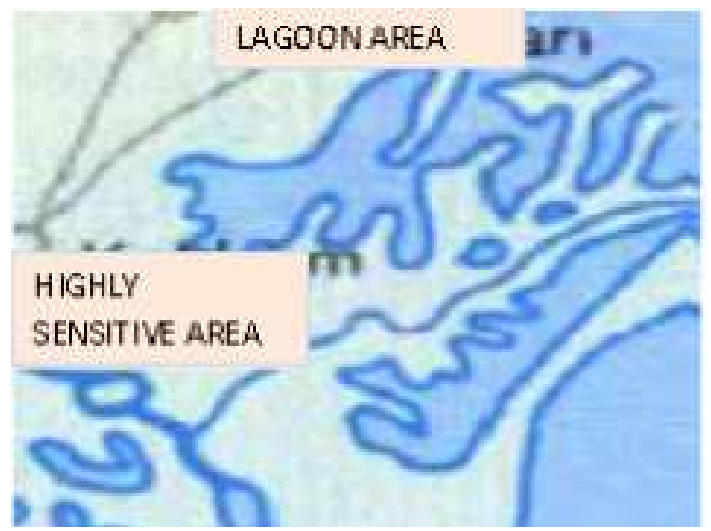

Figure 5. Map of the coast area, lagoon area, [23].

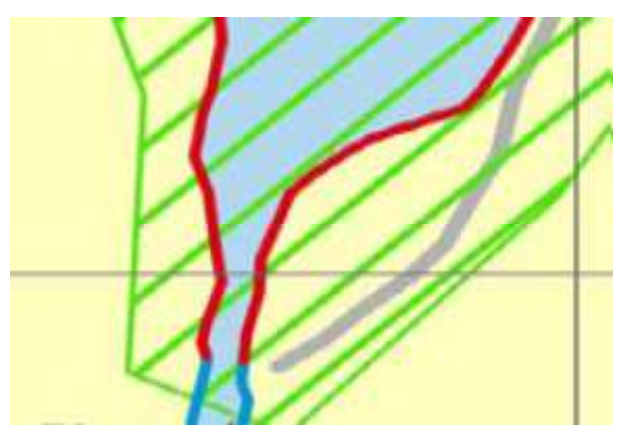

Figure 6. Sketch of the coast, [23].

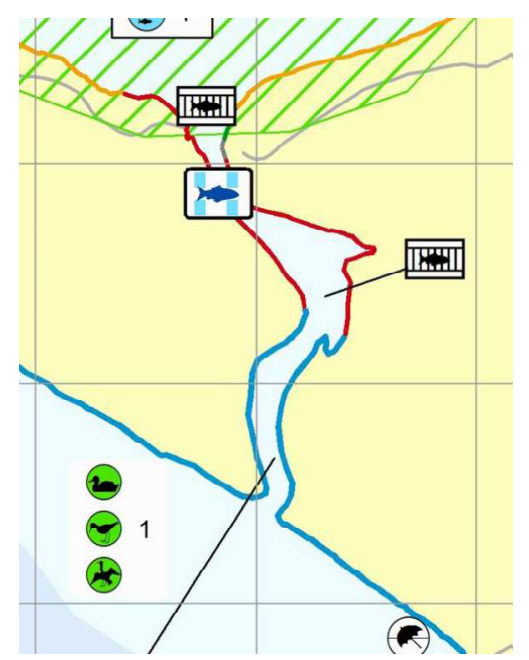

Figure 7. Sensivity of the coast, [23].

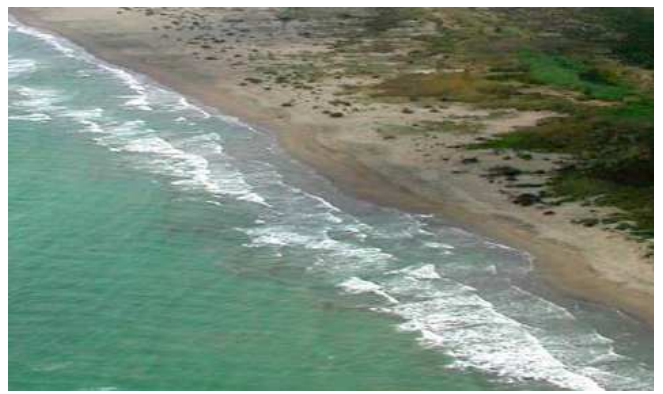

Figure 8. View of the coast, [23].

\subsection{Tracking Oil in Groundwater and Karst Areas}

Spilled oil can contaminate ground water, and this influence is stronger in Karst areas. Special techniques can applied for mitigation measures.

The groundwater areas are very sensitive and these areas must be studied in detail with considering existing wells. It is advised that simulation studies for attenuation of hydrocarbons in groundwater areas should be performed, since hydrocarbon contamination from the pipeline may result severe and extended damages in the environment.

The land geology of the pipeline surroundings must be known in detail, since oil spills on land can influence all neighboring area of the pipeline. Besides the geologic structures like karst areas increase the environmental sensivity of passage zones of the pipeline.

\section{Wildlife Care}

Wildlife may come into contact with spilled oil, especially on the surface of water or along shorelines or stream channels and banks. The numbers of individual animals and species affected will depend on the number of variable factors, such as location, the size of the spill, weather, wind and currents, habitats affected, and the time of year that the spill occurs. The most likely wildlife to be affected is birds, although invertebrates, fish, amphibians, reptiles and mammals can be affected. Response workers and the general public may encounter oiled wildlife and the public may 
desire or demand to assist in their collection and rehabilitation.

The pipeline owner will work with government authorities to collect and rehabilitate oiled wildlife, including establishment of a Wildlife Care Unit and provision of facilities, specialists and supplies for wildlife care. The Incident Commander (IC) in consultation with appropriate agencies will review all actions involving the collection and care of oiled wildlife.

A Wildlife Response Plan is prepared as part of this OSRP to provide assistance on the recovery and rehabilitation of oiled wildlife. Following an initial evaluation of the magnitude and severity of a potential oiled wildlife issue, the pipeline owner will work with agency representatives in the development of an incident specific Wildlife Care Plan that will address the requirements of the incident. This Plan will include consideration of organization and training of personnel, required permits, implementation of wildlife avoidance procedures (if appropriate), establishment of wildlife collection points, establishment of a public information telephone number, establishment of rehabilitation centers, logistics requirements, documentation procedures, and so on. It will be submitted to the IC and appropriate agencies for approval prior to implementation. The issues are:

- Permits,

- Volunteers,

- Land animals,

- Hazing,

- Collection of oiled wildlife,

- Disposition of dead animals,

- Resources,

- Wildlife documentation.

\section{Volunteers}

The pipeline owner will not utilize volunteer support directly; it will support the use of qualified and supervised volunteers by government authorities or a specialized wildlife rehabilitation organization. Notwithstanding, the pipeline owner is likely to hire local residents to support its response operations. All persons contracted will be given appropriate safety, job-specific training, and supervision. Additionally, the pipeline owner may support the use of qualified and supervised volunteers by appropriate government agencies.

\section{Training and Drills}

The company owns the pipeline must develop a comprehensive program in pollution prevention, oil spill response and response exercises. It is designed for regular employees, management personnel and the Response Contractor. The principal elements and components of the training program include:

Pollution Prevention Training for all personnel,

Spill Response Orientation Training for all personnel,
Introduction to the Incident Management System for all personnel,

Advanced Incident Management System training for incident management personnel,

Advanced spill response training for spill management and response personnel,

Specialized training for the oil spill Response Contractor,

Drills designed to exercise the OSRP including actual field exercises and agency participation.

Additional and comprehensive safety training is conducted by the company owns the Health and Safety department. Facility personnel are additionally trained for emergency response procedures particular to that installation. The issues are:

Local Emergency Services Training,

Skilled Support Personnel,

Specialist Employees,

Training Certification and Documentation,

Drills / Exercises.

Drills serve to evaluate the thoroughness and effectiveness of the emergency response component of the OSRP by testing under simulated conditions. Elements of the OSRP of drills include:

- Response structure and organization,

- Notifications and communications,

- Equipment capability and response times,

- Adequacy of action plans,

- Public relations,

- Emergency medical services,

- Evacuation,

- Drill Records,

- Verification of Equipment Maintenance.

Types of Oil Spill Response Exercises:

- Notification Exercise,

- Facility Table Top,

- Trans-Boundary Table Top,

- Equipment Deployment Exercise (Non-Marine),

- Equipment Deployment Exercise (Marine).

\section{Protection of Cultural Heritage}

The laws for the Protection of Cultural and Natural Assets provides for the protection and evaluation of movable and immovable cultural properties belonging to the public.

In case of oil spills, specific procedures must be defined in the document of Pipeline Environmental Sensitivity and Response Guidance. These measures are designed:

1. notify the responder of sites having cultural heritage value,

2. notify the proper authorities as to potential operations in a particular site area (all phone numbers and contact information is provided in the Spill Response Contacts Database),

3. restrict excavation activities in these areas,

4. provide for alternative response measures, avoid any damaging measures and equipment,

5. restore the area if altered. 


\section{Further Issues}

The following local issues are also part a comprehensive OSRP, they must include into the plan:

- Legal Framework,

- OSRP Requirements,

- Pipeline and Marine Terminal Description,

- Oil Properties,

- Environmental Risk and Sensitivity,

- Pipeline Risk Evaluation,

- Potential Spill Volumes,

- Pipeline Environmental Sensitivity,

- Marine Risk Evaluation,

- Response Strategy and Scenarios,

- Documentation,

- Public Relations Management,

- Introduction,

- Authorized Spokespersons,

- Media and Public Relations Support,

- Information Centre,

- Communications Systems,

- Media / Public Affairs Support,

- General Public Relations Guidelines,

- Contractor Employees,

- Media and Community Relations Guidelines,

- Crisis Communication Pitfalls,

- Common Questions and Possible Responses,

- Community Relations / Business Response Plan,

- Response Decision Guidance,

- Contacts For Notification and Services,

- Response Equipment,

- Tier 1 Response Kits,

- Truck Spill Kits,

- Tier 2 Response Depot Equipment,

- Waste Management,

- Material Safety Data Sheets

- Crude Oil,

- Diesel Oil,

- Forms Catalogue.

\section{Conclusion}

The methodology presented is covering the structure of OSRP plan even with onshore and offshore containment sites. The paper has sufficient information to prepare an OSRP for crude oil pipeline. A case study is not considered, however the information in the report can lead a comprehensive OSRP. The detailed and structured tool for preparing an OSRP is prepared. A specific example is not presented, however the information presented can lead a comprehensive OSRP.

\section{References}

[1] T. Ihaksi, T. Kokkonen, I. Helle, A. Jolma, T. Lecklin and S. Kuikka, Combining Conservation Value, Vulnerability, and Effectiveness of Mitigation Actions in Spatial Conservation Decisions: An application to Coastal Oil Spill Combating.
Environmental Management 47: 802-813, 2011.

[2] O. F. Knudsen and B. Hassler, IMO legislation and its implementation: Accident risk, vessel deficiencies and national administrative practices, Marine Policy, 35(2): 201207, 2011.

[3] T. Kokkonen, T. Ihaksi, A. Jolma and S. Kuikka, Dynamic mapping of nature values to support prioritization of coastal oil combating. Environmental Modelling\& Software 25: 248$257,2010$.

[4] S. E. Chang, J. Stone, K. Demes, and M. Piscitelli, Consequences of oil spills: a review and framework for informing planning. Ecology and Society 19(2): 26, (http://dx.doi.org/10.5751/ES-06406-190226), 2014.

[5] American Petroleum Institute, Oil spill response: options for minimizing adverse ecological impacts. American Petroleum Institute, Washington, D.C., USA, 1985.

[6] G. B. Assaf, B. G. Kroetch, and S. C. Mathur, Nonmarket valuations of accidental oil spills: a survey of economic and legal principles. Marine Resource Economics 2(3):211-237, 1986.

[7] British Columbia Government (BCG), Requirements for British Columbia to consider support for heavy oil pipelines. Provincial document. British Columbia Government, Victoria, British Columbia, Canada, (http://www.env.gov.bc.ca/main/docs/2012/TechnicalAnalysisHeavyOilPipeline_120723.pdf), 2012.

[8] British Columbia Ministry of Environment (BC-MOE), British Columbia marine oil spill response plan, Provincial document, British Columbia Ministry of Environment, Victoria, British Columbia, Canada, 2013.

[9] T. M. Brody, P. Di Bianca and J. Krysa, Analysis of inland crude oil spill threats, vulnerabilities, and emergency response in the Midwest United States. Risk analysis 32(10):1741-1749, (http://dx.doi.org/10.1111/j.1539-6924.2012.01813.x ), 2012.

[10] Conversations for Responsible Economic Development (CRED), Assessing the risks of Kinder Morgan's proposed new Trans Mountain pipeline. Conversations for Responsible Economic Development, Vancouver, British Columbia, Canada, (http://credbc.ca/assessing-the-risks/), 2013.

[11] S. M. Cheong, A social assessment of the Hebei-Spirit oil spill, GeoJournal 76:539-549. http://dx.doi.org/10.1007/s10708010-9368-4), 2011.

[12] F. Lord, S. Tuler, T. Webler and K. Dow, Unnecessarily neglected in planning: illustration of a practical approach to identify human dimension impacts of marine oil spills. Journal of Environmental Assessment Policy and Management 14(2):123, (http://dx.doi.org/10.1142/S1464333212500123), 2012.

[13] W. E. Wilhelm WE and A. V. Srinivasa, Prescribing tactical response for oil spill cleanup operations. Management Science 43:386-402, 1997.

[14] C. A. Brebbia, Oil spill modeling and processes. WIT Press: UK, 2001.

[15] M. Fingas M. The basics of oil spill cleanup. Lewis: New York, 2001.

[16] B. Ornitz and M. Champ M. Oil spills first principles: prevention and best response. Elsevier: Netherlands, 2003. 
[17] D. Mackay, I. A. Buis, R. Mascarenhas R and S. Paterson, Oil spill processes and models: Environment Canada, Manuscript Report No 8. EE-8; Ottawa, Ontario, 1980.

[18] Z. Zhong Z and Y. You, Oil spill response planning with consideration of physicochemical evolution of the oil slick: A multiobjective optimization approach, ANL/MCS-P1786-0810, Mathematics and Computer Science Division, Argonne National Laboratory, 2010.

[19] N. P. Ventikos, E. Vergetis, H. N. Psaraftis and G.Triantafyllou, A high-level synthesis of oil spill response equipment and countermeasures. Journal of Hazardous Materials; 107:51-58, 2004.

[20] R. G. Pond, D. V. Aurand and J. A. Kraly, Ecological risk assessment principles applied to oil spill response planning in the Galveston Bay Area, Texas General Land Office, Austin, Texas, 2000.

[21] Z. Zhong and F. You, Oil spill response planning with consideration of physicochemical evolution of the oil slick: A multiobjective optimization approach, Computers \& Chemical Engineering, 08/2011; 35(8):1614-1630. DOI: 10.1016/j.compchemeng.2011.01.009, 2011.

[22] H. M. Cekirge, Pipelines, Maltepe Uni., Int. Rep. 1/2, Istanbul, 2010.

[23] H. M. Cekirge, Oil spills and shorelines, Maltepe Uni., Int. Rep. 1/3, Istanbul, 2010. 